\author{
С.В. Клейн ${ }^{1,2}$, Э.В. Седусова ${ }^{1}$, Т.М.Лебедева ${ }^{3}$, В.Г.Новоселов ${ }^{3}$ \\ ${ }^{1}$ ФБУН «Федеральный научный центр медико-профрилактических технологий \\ управления рисками здоровью населения»,

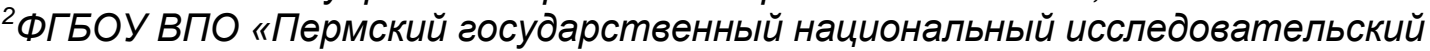 \\ университет»,

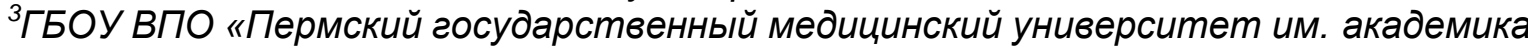 \\ Е.А.Вагнера» Минздрава России, \\ 2. Пермь, Россия

\section{ОПЫТ ФОРМИРОВАНИЯ ДОКАЗАТЕЛЬНОЙ БАЗЫ ВРЕДА ЗДОРОВЬЮ НАСЕЛЕНИЯ В УСЛОВИЯХ ЗАГРЯЗНЕНИЯ ПИТЬЕВОЙ ВОДЫ ХЛОРОРГАНИЧЕСКИМИ СОЕДИНЕНИЯМИ}

\begin{abstract}
Аннотация (Резюме). В статье предложен порядок установления вреда здоровью населения, потребляющего питьевую воду, содержащую хлорорганические соединения - продукты гиперхлорирования. Порядок включает в себя следующие этапы: установление обстоятельств формирования нарушений здоровья; оценка качества питьевой воды; оценка риска здоровью населения; проведение медико-биологических исследований (определение содержания загрязняющих веществ в биосредах населения, изучение биохимического и гематологического профиля населения, клинико-функциональное обследование населения); обработка совокупности информации по видам эфффектов, критериям воздействия, моделям причинно-следственных связей «экспозиция-эффект». Описаны результаты апробации алгоритма установления вреда здоровью населения в результате загрязнения питьевой воды продуктами гиперхлорирования в г. Нытва Пермского края. Полученные результаты могут быть использованы в ходе надзорной деятельности и административных расследований, а также в судебном производстве при защите прав потребителей коммунальных услуг питьевого водоснабжения и возмещении вреда здоровью в результате предоставления питьевой воды ненадлежащего качества.
\end{abstract}

Ключевые слова: питьевая вода; хлорорганические соединения; оценка риска; вред здоровью.

\author{
(C) S.V. Kleyn ${ }^{1,2}$, E.V. Sedusova ${ }^{1}$, T.M. Lebedeva ${ }^{3}$ \\ 1 "Federal Scientific Center for Medical and Preventive Population Health Risk Management \\ Technologies", \\ 2 "Perm State National Research University", \\ 3 "Perm State Medical University named after E.A. Wagner"
}

Perm, Russia

\title{
EXPERIENCE OF FORMING OF THE EVIDENCE BASE OF HARM TO PUBLIC HEALTH CAUSED BY CHLORORGANIC CONTAMINATION OF DRINKING WATER
}

Abstract. This paper provides the algorithm for establishing harm to the health of population consuming drinking water contaminated with chlororganics - the hyperchlorination products. The algorithm includes establishment of conditions under which health harm is formed; drinking water quality assessment; public health risk assessment; conduction of medical and biological studies (determination of contaminants in biological media of the population, the study of biochemical and hematological profile of the population, clinical and functional examination of the population); processing aggregate information on types of effects, criteria of exposure, and cause-and-effect relationship models. The results of the use of this algorithm in Nytva in Perm Krai are described. The obtained results can be used in supervisory activities and administrative investigations as well as in court proceedings to protect the rights of customers of public services to drinking water supply and compensate injuries caused by providing drinking water of improper quality.

Keywords: drinking water, chlororganics, risk assessment, harm to health. 
Введение. Право на возмещение вреда, причиненного жизни, здоровью вследствие необеспечения безопасности товара, работы, услуги, в т.ч. вследствие предоставления коммунальных услуг по водоснабжению ненадлежащего качества закреплено Законом РФ от 07.02.1992 N 2300-1 «О защите прав потребителей».

В соответствии с правилами предоставления коммунальных услуг (утв. Постановлением Правительства РФ от 06.05.2011 N 354) вред, причиненный жизни, здоровью потребителя вследствие нарушения качества предоставления коммунальных услуг или вследствие непредоставления потребителю полной и достоверной информации о предоставляемых коммунальных услугах, подлежит возмещению исполнителем в полном объеме независимо от вины исполнителя.

Однако судебная практика по возмещению вреда здоровью, причиненного вследствие нарушения качества предоставления услуг по водоснабжению, незначительна. Проблема возмещения вреда здоровью объясняется сложностью доказательства факта причинения вреда здоровью вследствие нарушения качества предоставления коммунальных услуг.

В настоящее время нормативно не регламентирован порядок формирования доказательственной базы возникновения вреда здоровью граждан, обусловленного воздействием факторов среды обитания. Вместе с тем, закреплены основные принципы доказательства вреда здоровью при негативном воздействии факторов среды обитания, накоплен значительный фактический материал по видам нарушений здоровью гражданина под воздействием факторов среды обитания, развиваются методы биологического мониторинга с обоснованием маркеров воздействия и маркеров ответа, внедряется методология оценки риска здоровью населения для управления качеством среды обитания и сохранения здоровья населения $[1,3,4,6,7]$. При этом, установление и доказывание вреда здоровью вследствие предоставления коммунальных услуг ненадлежащего качества требует 
собственных подходов.

Цель исследования: отработка методических подходов к формированию доказательной базы причинения вреда здоровью населения, возникающего при потреблении питьевой воды, содержащей хлорорганические соединения (ХОС) - продукты гиперхлорирования.

Методы и материалы исследования. Формирование доказательной базы осуществлялось с учетом Методических указаний «Порядок применения результатов медико-биологических исследований для доказательства причинения вреда здоровью населения негативным воздействием химических факторов среды обитания» (МУ 2.1.10.3165-14).

Установление вреда здоровью населения, потребляющего питьевую воду, несоответствующую гигиеническим требованиям, включало следующие этапы:

- установление обстоятельств формирования нарушений здоровья (факта причинения вреда);

- оценка качества питьевой воды и анализ информации о потенциальных источниках ухудшения питьевой воды, оценка соответствия деятельности хозяйствующих субъектов-источников воздействия на питьевую воду требованиям действующего законодательства;

- оценка риска здоровью населения с установлением приоритетных факторов опасности и вероятных эффектов (ответов) в состоянии здоровья, определяемых уровнем риска для здоровья;

- проведение медико-биологических исследований для установления вида и тяжести вреда здоровью (определение содержания загрязняющих веществ в биосредах населения, изучение биохимического и гематологического профиля населения, клинико-функциональное обследование населения);

- обработка совокупности информации по видам эффектов, критериям воздействия, моделям причинно-следственных связей «экспозиция-эффект» с 
формированием доказательной базы наличия или отсутствия вреда, обусловленного питьевой водой, причиной ухудшения которой стала деятельность конкретных хозяйствующих субъектов.

Установление и доказывание вреда здоровью населения, потребляющего питьевую воду с продуктами гиперхлорирования, проводилось на примере г. Нытва Пермского края. Водоснабжение г. Нытва осуществляется из поверхностного источника водоснабжения - пруда (водный объект первой категории, созданный на p. Нытва). Для обеззараживания питьевой воды используется хлорирование.

Для гигиенической оценки качества питьевой воды г. Нытва использовали данные ФБУЗ «Центр гигиены и эпидемиологии в Пермскому крае», полученные в рамках социально-гигиенического мониторинга, и результаты направленных исследований ФБУН «ФНЦ медикопрофилактических технологий управления рисками здоровью населения» в дошкольных образовательных учреждениях (из крана ДОУ и из колонки).

Оценка содержания анализируемых соединений в пробах питьевой воды выполнена на соответствие СанПиН 2.1.4.1074-01 «Питьевая вода. Гигиенические требования к качеству воды централизованных систем питьевого водоснабжения. Контроль качества» и ГН 2.1.5.1315-03 «Предельно допустимые концентрации (ПДК) химических веществ в воде водных объектов хозяйственно-питьевого и культурно-бытового водопользования».

Содержание в питьевой воде хлорорганических соединений определяли методом газовой хроматографии в соответствии с методиками выполнения измерений (МУК 4.1.646-96), прошедшими метрологическую аттестацию в соответствии с ГОСТ Р 8.563-96.

В качестве контингента исследования выбрали детей в возрасте 4-7 лет (93 ребенка), постоянно проживающих в г. Нытва, посещающих ДОУ и использующих для питьевых нужд воду с содержанием продуктов 
гиперхлорирования. В группу сравнения вошли 46 детей в возрасте 4-7 лет, проживающие в с. Сива и посещающие ДОУ. Качество питьевого водоснабжения территории сравнения соответствовало санитарногигиеническим требованиям. Группы сравнения были аналогичны исследуемым основным группам по половозрастному составу, социальноэкономическим условиям жизни, но дети не были подвержены неблагоприятному воздействию факторов питьевой воды.

Оценку риска для здоровья населения проводили в соответствии с методическими подходами, изложенными в Р 2.1.10.1920-04 «Руководство по оценке риска для здоровья населения при воздействии химических веществ, загрязняющих окружающую среду».

Расчет показателей риска проводился по результатам лабораторных исследований качества питьевой воды системы центрального хозяйственнопитьевого водоснабжения, подаваемой населению г. Нытва, по мониторинговым данным ФБУЗ «Центр гигиены и эпидемиологии в Пермском крае» за 2013 г. и 1-ое полугодие 2014 г., а также по результатам натурных замеров ИЛЦ ФБУН «ФНЦ медико-профилактических технологий управления рисками здоровью населения» на соответствие гигиеническим нормативам в точках расположения ДОУ (г. Нытва Пермского края).

Заболеваемость детского населения по тем классам болезней и нозологиям, которые на этапе оценки риска были определены как этиологически связанные с факторами риска, оценивали по данным территориального фонда обязательного медицинского страхования (ФОМС) и данным государственной статистической отчетности ЛПУ (форма № 12) за 2011-2013 гг.

Исследование содержания хлорорганических соединений в крови у обследуемых лиц выполнено методом газовой хроматографии в соответствии с методиками выполнения измерений (МУК 4.1.2115-06), прошедшими метрологическую аттестацию в соответствии с ГОСТ Р 8.563-96. Оценку 
установленных уровней содержания хлорорганических соединений в крови осуществляли на основании сравнительного анализа с результатами у детей группы сравнения.

Причинно-следственная связь между концентрацией хлорорганических соединений в питьевой воде и изменением концентрации этих веществ в крови у детей устанавливалась с помощью линейного регрессионного анализа. Для определения параметров модели использовались данные мониторинга по концентрациям хлороформа в питьевой воде территорий Пермского края и данные ФБУН «ФНЦ медико-профилактических технологий управления рисками здоровью населения» по концентрациям хлороформа в крови детей 2-7 лет, проживающих на данных территориях, за $2011-2014$ гг.

Изучение биохимического и гематологического профиля у детей выполняли в соответствии с обязательным соблюдением этических норм, изложенных в Хельсинкской декларации 1975 года с дополнениями 1983 года. Объем исследований включал лабораторные показатели, адекватные токсикологическому профилю загрязнения питьевой воды и определяемые унифицированными общеклиническими, биохимическими и иммунологическими методами [2, 5]. В качестве критериев оценки выраженности и частоты встречаемости отклонений лабораторных показателей использованы возрастные физиологические уровни и уровни лабораторных показателей детей группы сравнения.

Выявление и оценку связи между изменением клинико-лабораторных показателей у детей и концентраций хлорорганических соединений в крови выполняли на основе расчета показателя отношения шансов (OR) и его доверительного интервала (DI). Критерием наличия связи «концентрация хлорорганических соединений в крови - показатель эффекта» являлось $\mathrm{OR} \geq 1$. 
Обоснование маркеров эффекта осуществляли на основании оценки параметров зависимости изменения показателя отношения шансов от концентрации хлорорганических соединений в крови, описываемой регрессионной моделью в виде экспоненциальной функции. В качестве критерия для проверки статистических гипотез использовали критерий Фишера (F). Различия считали статистически значимыми при $\mathrm{p} \leq 0,5$.

Для выявления клинических особенностей соматического статуса детей г. Нытва проводили медико-социальное анкетирование, осмотр педиатром, гастроэнтерологом, неврологом с оценкой соматического статуса, физического развития, групп здоровья ребенка, анализ карт развития детей (форма №112/y), оценку психоэмоционального напряжения, электрокардиографию, кардиоинтервалографию, электроэнцефалографическое исследование, ультразвуковое исследование щитовидной железы, желчного пузыря, поджелудочной железы, печени, селезенки, надпочечников, почек.

Результаты исследования: По данным ФБУЗ «Центр гигиены и эпидемиологии в Пермском крае» на территории г. Нытва наблюдалось превышение гигиенических нормативов качества питьевой воды по хлороформу в 2013 г. до 6,2 ПДК, в первом полугодии 2014 г. - до 7,2 ПДК. Процент нестандартных проб питьевой воды по хлороформу в 2013 г. составил от 78,6 до 100,0\%, в первом полугодии 2014 г. - от 83,3 до 100,0\%. По данным ФБУН «ФНЦ медико-профилактических технологий управления рисками здоровью населения» в первом полугодии 2014 г. на территории г. Нытва наблюдалось превышение гигиенических нормативов по хлороформу во всех пробах, отобранных в ДОУ, до 12,3 ПДК и в колонке до 11 ПДК, по дихлорбромметану - в пробах, отобранных в ДОУ, до 4,3 ПДК и в колонке до 3,6 ПДК.

Формируемый суммарный индивидуальный канцерогенный риск соответствовал предельно допустимому уровню риска - до $3,58 \times 10^{-5}$. 
Основной вклад в величину суммарного индивидуального канцерогенного риска вносят дихлорбромметан $(63,1 \%)$, хлороформ $(21,5 \%)$ и дибромхлорметан (11,3\%). При пероральном поступлении химических веществ с питьевой водой у детей г. Нытва формируются неприемлемые уровни неканцерогенного риска в отношении заболеваний печени (HI до $1,74)$, почек (НI до 1,71), эндокринной системы, центральной нервной системы (ЦНС) и системы крови (НI до 1,47), при допустимом значении индекса опасности 1). Основной вклад в величину индекса опасности вносит хлороформ: 85,96\% в величину индекса опасности для нарушений со стороны почек, $100 \%$ - гормональной системы, ЦНС и системы крови, $84,6 \%$ - печени.

По данным ФОМС за 2011-2013 г. обращаемость детского населения г. Нытва за медицинской помощью в связи с заболеваниями нервной системы превышала соответствующие показатели контрольной территории в 3,46-5,4 раза, заболеваниями печени - в 1,38-1,89 раза, мочеполовой системы - в 1,271,94 раза, заболеваниями крови, кроветворных органов и отдельными нарушениями, вовлекающими иммунный механизм, - в 1,2-3,9 раза.

Во всех исследуемых пробах крови детей г. Нытва, обнаружены дибромхлорметан, хлороформ и тетрахлорметан. В крови детей г. Нытва зарегистрированы превышения относительно группы сравнения по дибромхлорметану $(\mathrm{p}<0,01)$, хлороформу в 2 раза $(\mathrm{p}<0,01)$ и тетрахлорметану в 5 раз $(\mathrm{p}<0,00)$. Установленное количество биопроб крови с повышенным содержанием хлорорганических соединений выше уровней группы сравнения составило от 5,1\% до 90,9\%, в том числе дибромхлорметана - в 15,9 \% проб, хлороформа - в 47,7 \% проб, тетрахлорметана - в 90,9 \% проб. Оценка связи между экспозицией хлорорганическими веществами, поступающими с питьевой водой и уровнем их содержания в крови детей, свидетельствует о наличии достоверной зависимости концентрации хлороформа в крови от 
концентрации хлороформа в питьевой воде $(y=0,00188+0,01782 x, F=5,356$, $p=0,035$.

Анализ результатов биохимических и иммуноферментных исследований показал, что у детей г. Нытва регистрируются отклонения показателей относительно аналогичных показателей детей группы сравнения, характеризующих негативные эффекты, доказано связанные с повышенной концентрацией хлорорганических соединений в крови, которые проявляются в виде:

нарушения баланса оксидантных и антиокислительных реакций в организме: повышение гидроперекиси липидов в сыворотке крови, 8гидрокси-2-деоксигуанозина в моче, повышение глутатионпероксидазы (ГлПО), снижение глутатион-S-трансферазы (ГлST) и супероксиддисмутазы (СОД) сыворотки крови;

- дисбаланса нейромедиаторов, регулирующих процессы возбуждения и торможения в ЦНС: повышение глутамата, снижение гаммааминомасляной кислоты ( $\gamma$-АМК) в сыворотке крови;

- тенденции к нарушению фильтрационной функции почек: повышение скорости клубочковой фильтрации;

- активации процесса цитолиза, сопровождающегося воспалительной реакцией: повышение аспартатаминотрансферазы (АСАТ) в сыворотке крови;

- цитогенетических нарушений, характеризующихся повышенной частотой клеток с цитогенетическими аномалиями на фоне усиления деструктивных изменений в клеточной популяции на уровне ДНК.

При этом различия в указанных показателях в исследуемых группах и группах сравнения были достоверны и составили $1,1-5$ раз.

У детей г. Нытва установлены достоверные причинно-следственные связи «маркер экспозиции - маркер эффекта» (таблица). 
Таблица

\section{Параметры моделей зависимости «маркер экспозиции - маркер эффекта» у детей г. Нытвы}

\begin{tabular}{|c|c|c|c|c|c|}
\hline \multirow{2}{*}{$\begin{array}{c}\text { Маркер } \\
\text { экспозиции } \\
\text { (кровь) }\end{array}$} & \multirow{2}{*}{$\begin{array}{l}\text { Маркер } \\
\text { эффекта }\end{array}$} & \multirow{2}{*}{$\begin{array}{c}\text { Направление } \\
\text { изменения показателя }\end{array}$} & \multicolumn{3}{|c|}{ Параметры модели } \\
\hline & & & $\mathrm{F}$ & $\mathrm{p}$ & $\mathrm{R}^{2}$ \\
\hline Хлороформ & 8-гидрокси-2-деоксигуанозин & Повышение & 72,144 & 0,000 & 0,507 \\
\hline Хлороформ & Гамма-аминомасляная кислота & Понижение & 725,504 & 0,000 & 0,914 \\
\hline Хлороформ & Гидроперикиси липидов & Повышение & 520,886 & 0,000 & 0,899 \\
\hline Хлороформ & СРБ высокоч. & Повышение & 48,400 & 0,000 & 0,386 \\
\hline Хлороформ & Глутатион-S-трансфераза & Понижение & 438,959 & 0,000 & 0,882 \\
\hline Хлороформ & Глутатионпероксидаза & Повышение & 102,220 & 0,000 & 0,634 \\
\hline Хлороформ & Скорость клубочковой фильтрации & Повышение & 241,725 & 0,000 & 0,764 \\
\hline Хлороформ & Супероксиддисмутаза & Понижение & 17,769 & 0,000 & 0,231 \\
\hline Четыреххлористый углерод & 8-гидрокси-2-деоксигуанозин & Повышение & 82,782 & 0,000 & 0,664 \\
\hline Четыреххлористый углерод & Глутатионпероксидаза & Повышение & 11,454 & 0,003 & 0,167 \\
\hline Четыреххлористый углерод & СРБ высокоч. & Повышение & 76,195 & 0,000 & 0,524 \\
\hline Четыреххлористый углерод & Скорость клубочковой фильтрации & Повышение & 121,854 & 0,000 & 0,623 \\
\hline
\end{tabular}

По результатам иммунологического исследования выявлены нарушения:

- клеточного звена иммунитета: снижение фагоцитарного числа (ФЧ), а также угнетение Т-клеточных рецепторов CD4+, CD25+, CD95+;

- гуморального звена иммунитета (преимущественное угнетение содержания $\operatorname{IgG})$;

- специфической чувствительности к компонентам факторной нагрузки (повышение содержания антител к хлороформу по критерию IgG);

- уровня маркеров онкопролиферации (СА199) и гормональной и медиаторной регуляции (Т4 свободный, серотонин). Они достоверно повышены по отношению к референтному уровню и контролю.

Результаты генетического анализа полиморфизма генов выявили преимущественные генные нарушения у детей г.Нытва по критерию распространенности минорного аллеля генов цитохрома CYP1A1, гена рецептора запуска апоптоза (FAS), гена металлопротеиназы MMP, гена фактора гистосовместимости HLA DR1, гена эстрогенового рецептора (ESR1). 
Таким образом, для наблюдаемой зоны типичны супрессорные нарушения иммунного статуса, повышение специфической чувствительности к хлороформу, уровня маркеров онкопролиферации и содержания медиаторов нейро-гормональной регуляции, а также генетические нарушения детоксикации органических токсикантов, эндокринной регуляции, функции иммунного контроля за апоптозом и онкогенезом. Показателями факторной нагрузки, достоверно изменяющими значения показателей иммунитета, являются хлороформ, четыреххлористый углерод.

Установлена достоверная причинно-следственная связь между:

- повышением относительного и абсолютного фагоцитоза при увеличении концентрации четыреххлористого углерода $(\mathrm{R} 2=0,31-0,70$ при $\mathrm{p}<0,05)$, хлороформа ( $\mathrm{R} 2=0,67, \mathrm{p}<0,05)$ в крови;

- понижением концентрации $\operatorname{IgM}$ при увеличении концентрации хлороформа в крови $(\mathrm{R} 2=0,27, \mathrm{p}<0,05)$, понижением концентрации IgG при увеличении концентрации тетрахлорметана в крови $(\mathrm{R} 2=0,71, \mathrm{p}<0,05)$;

- понижением CD4+, CD25+, CD95+ при увеличении концентрации хлороформа $(\mathrm{R} 2=0,68-0,87, \mathrm{p}<0,05)$;

- повышением содержания серотонина в крови при увеличении концентрации хлороформа (R2=0,22-0,43, p<0,05);

- повышением концентрации $\operatorname{IgG}$ к хлороформу при увеличении концентрации тетрахлорметана в крови (R2=0,50 при $\mathrm{p}<0,05)$.

Результаты клинических исследований свидетельствовали, что наиболее часто у обследованных детей г. Нытва встречались заболевания желудочно-кишечного тракта, нервной системы, болезни эндокринной системы.

Патология желудочно-кишечного тракта выявлена обследованных детей. При этом у детей, проживающих в г. Нытва, доминировала функциональная диспепсия, которая встречалась практически у каждого второго ребенка $(45,2 \%)$, что было достоверно в 3,0 раза чаще 
группы сравнения $(\mathrm{p}=0,001)$. Поражения гепато-билиарной сферы диагностировались у $32,3 \%$ детей, проживающих в г. Нытва, что в 1,7 раза чаще группы сравнения $(\mathrm{p}=0,12)$.

Болезни нервной системы регистрировались у 20,65\% детей, проживающих в г. Нытва, что достоверно в 2,25 раза чаще, чем в группе сравнения $(\mathrm{p}=0,01)$. При этом у детей, проживающих в г. Нытва, астеноневротический синдром встречался у каждого третьего ребенка $(35,49 \%)$, что превышало показатели группы сравнения в 16,3 раза $(\mathrm{p}=0,00)$. Проявления вегетативной дистонии и неврозоподобного синдрома отмечались у детей, проживающих в г. Нытва, с одинаковой частотой 7,53\%, в то время как в сравниваемой группе только 1 ребенок имел вегетативные нарушения $(2,18 \%, p=0,20)$.

Патология эндокринной системы, которая была представлена изменениями роста и нарушением питания, встречалась в г.Нытва у 17,35\% детей, что в 3,4 раза чаще, чем в группе сравнения $(\mathrm{p}=0,029)$. У детей, проживающих в г. Нытва, в 2,2-3,7 раза чаще регистрировалась высокорослость и избыточное питание ( $\mathrm{p}=0,15-0,27)$.

Установлены достоверные причинно-следственные связи вероятности развития патологических эффектов от:

- заболеваний пищеварительного тракта в виде функциональной диспепсии при повышенном содержании в крови хлороформа и четыреххлористого углерода $\left(\mathrm{R}^{2}=0,403-0,61 ; 51,27 \leq \mathrm{F} \geq 115,45 ; \quad \mathrm{p}=0,00\right) \quad$ и билиарной дисфункции при увеличении концентрации в крови четыреххлористого углерода $\left(\mathrm{R}^{2}=0,92 ; \mathrm{F}=720,83 ; \mathrm{p}=0,00\right)$;

- болезней нервной системы, проявлявшихся неврозоподобным и астено-невротическим синдромами, при повышенном содержании в крови хлороформа и четыреххлористого углерода $\left(\mathrm{R}^{2}=0,19-0,73 ; 17,70 \leq \mathrm{F} \geq 136,25\right.$; $\mathrm{p}=0,00)$; 
- болезней эндокринной системы в виде избыточного питания при повышенном содержании в крови хлороформа $\left(\mathrm{R}^{2}=0,59 ; \mathrm{F}=48,98 ; \mathrm{p}=0,00\right)$.

Пошаговая реализация алгоритма доказательства вреда здоровью детского населения г. Нытва, потребляющего питьевую воду с наличием продуктов гиперхлорирования, с корректным выбором и анализом маркеров экспозиции и маркеров ответа, являющихся связующими звеньями между уровнем факторов риска и нарушениями здоровья, позволили сформировать доказательную базу нанесения вреда здоровью детского населения г. Нытва:

- идентифицирован источник опасности - питьевая вода, качество которой не соответствует санитарно-гигиеническим требованиям по показателям содержания хлороформа и дибромхлорметана концентрации которых превышали гигиенические нормативы и безопасные для здоровья уровни;

- установлено, что хлорорганические соединения образуются в питьевой воде в результате хлорирования воды источника питьевого водоснабжения;

- определено, что хлорорганические соединения, содержащиеся в питьевой воде, формируют неканцерогенный риск, превышают допустимый уровень в отношении заболеваний печени, почек, центральной нервной системы, эндокринной системы и системы крови. Основной вклад в показатели риска для здоровья вносит хлороформ (85-100\%);

- в крови детского населения, постоянно потребляющего исследуемую питьевую воду и подверженного риску нарушений здоровья, зарегистрированы хлорорганические соединения на уровнях, достоверно более высоких, чем в группе сравнения (дети, не потребляющие загрязненную питьевую воду), $\mathrm{p}<0,05$;

- выявлено, что присутствие примесей в крови достоверно ухудшало систему лабораторных показателей гомеостаза; при этом установленные методами математической статистики связи «контаминант в крови - 
лабораторный показатель» были биологически правдоподобны, адекватны имеющимся научным данным и устойчивы;

- доказано, что экспонируемое детское население характеризуется повышенной заболеваемостью, ассоциированной с факторами риска и обоснованной с учетом системы клинических, лабораторных и функциональных показателей, которые имели достоверные биологически оправданные связи с экспозицией (маркерами экспозиции);

- данные анамнеза и результаты анкетирования не выявили иных достоверных провоцирующих факторов в выявленных нарушениях здоровья.

Использование методических подходов и результатов углубленных медико-биологических исследований позволило доказать вред здоровью детского населения, потребляющего питьевую воду ненадлежащего качества на популяционном и на индивидуальном уровне.

Выводы. Последовательный и системный сбор данных о присутствии опасных химических веществ в питьевых водах, установление недопустимого риска для здоровья в условиях загрязнения питьевой воды, выявление контаминации биологических сред организма идентифицированными в питьевых водах химическими примесями, установление связи между маркерами экспозиции и показателями нарушения здоровья позволяет сформировать доказательную базу наличия вреда здоровью. Эти материалы могут быть использованы для досудебной и судебной защиты прав граждан на благоприятную среду обитания, в том числе безопасное питьевое водоснабжение.

На индивидуальном уровне вред доказан для 31 обследованного ребенка (из 93), в том числе в 25 случаях вред выражен в виде заболеваний ЦНС, в 10 случаях - заболеваний эндокринной системы, в 8 - заболеваний печени, в 2 - заболеваний почек.

Полученные результаты легли в основу принятия решения о мерах по улучшению питьевого водоснабжения поселения и медико- 
профилактической помощи детям. При этом для контингентов риска с разно выраженным вредом здоровью были разработаны дифференцированные программы профилактики и коррекции здоровья.

\section{Список литературы:}

1. Зайцева Н.В., Май И.В., Клейн С.В. К вопросу установления и доказательства здоровью населения при выявлении неприемлемого риска, обусловленного факторами среды обитания // Анализ риска здоровью.- 2013. - № 2. - С. 14-26.

2. Землянова М.А., Федорова Н.Е., Кольдибекова Ю.В. Биохимическоие маркеры негативных эффектов у детей при воздействии хлорорганических соединений, поступающих в организм с питьевой водой // Здоровье населения и среда обитания. - 2011. - № 9. - С. 33-37.

3. Май И.В., Зайцева Н.В., Клейн С.В., Седусова Э.В. Установление и доказательство вреда здоровью гражданина, наносимого негативным воздействием факторов среды обитания // Здоровье населения и среда обитания. -2013 . - №11. - С. 4-7.

4. Май И.В., Седусова Э.В. Опыт установления и доказывания в досудебном и судебном порядке вреда здоровью, наносимого использованием питьевой воды с продуктами гиперхлорирования // Известия Самарского научного центра РАН. - 2014. - Т. 16, № 5(2). - С. 902-906.

5. Онищенко Г.Г Гигиеническая индикация последствий для здоровья при внешнесредовой экспозиции химических факторов / Г.Г. Онищенко, Н.В. Зайцева, М.А. Землянова; под ред. Г.Г. Онищенко. - Пермь: Книжный формат, 2011. - $532 \mathrm{c}$.

6. Онищенко Г.Г., Зайцева Н.В., Май И.В. и др. Анализ риска здоровью в стратегии государственного социально-экономического развития: монография / под общ. ред. Онищенко Г.Г., Зайцевой Н.В. - М.; Пермь: Издво Перм. нац. исслед. политехн. ун-та, 2014. - 738 с.

7. Флетчер Р., Флетчер С., Вагнер Э. Клиническая эпидемиология. Основы доказательной медицины. - М.: Медиа Сфера, 1998. - С. 352.

\section{References}

1. Zaytseva N.V., May I.V., Kleyn S.V. K voprosu ustanovleniya i dokazatel'stva zdorov'yu naseleniya pri vyyavlenii nepriemlemogo riska, obuslovlennogo faktorami sredy obitaniya [To the question of determining and proving of the unacceptable population health risk caused by environmental factors]. Analiz riska zdorov'yu, 2013, no. 2, pp. 14-26 (in Russian).

2. Zemlyanova M.A., Fedorova N.E., Kol'dibekova Yu.V. Biokhimicheskoie markery negativnykh effektov u detey pri vozdeystvii khlororganicheskikh 
soedineniy, postupayushchikh $\mathrm{v}$ organizm s pit'evoy vodoy [Biochemical markers of negative effects in children under the influence of chloroorganics entering the organism through drinking water]. Zdorov'e naseleniya i sreda obitaniya, 2011, no. 9, pp. 33-37 (in Russian).

3. May I.V., Zaytseva N.V., Kleyn S.V., Sedusova E.V. Ustanovlenie i dokazatel'stvo vreda zdorov'yu grazhdanina, nanosimogo negativnym vozdeystviem faktorov sredy obitaniya [Determining and proving of the harm to a citizen`s health caused by the influence of unfavourable environmental factors]. Zdorov'e naseleniya i sreda obitaniya, 2013, no. 11, pp. 4-7 (in Russian).

4. May I.V., Sedusova E.V. Opyt ustanovleniya i dokazyvaniya v dosudebnom i sudebnom poryadke vreda zdorov'yu, nanosimogo ispol'zovaniem pit'evoy vody $\mathrm{s}$ produktami giperkhlorirovaniya [Experience of determining and proving of the harm to health caused by drinking water with hyperchlorination products]. Izvestiya Samarskogo nauchnogo tsentra RAN, 2014, vol. 16, no. 5(2), pp. 902-906 (in Russian).

5. Onishchenko G.G., Zaytseva N.V., Zemlyanova M.A. Gigienicheskaya indikatsiya posledstviy dlya zdorov'ya pri vneshnesredovoy ekspozitsii khimicheskikh faktorov [Hygienic indication of health consequences under external environmental chemical exposure. Edited by Onishchenko G.G.]. Perm: Knizhnyy format, 2011. 532 p. (in Russian).

6. Onishchenko G.G., Zaytseva N.V., May I.V. i dr. Analiz riska zdorov'yu v strategii gosudarstvennogo sotsial'no-ekonomicheskogo razvitiya: monografiya [Analysis of health risk in the strategy of state social-economical development: monograph. Edited by Onishchenko G.G., Zaytseva N.V.]. Moscow; Perm': Izd-vo Perm. nats. issled. politekhn. un-ta, 2014. p. 738. (in Russian).

7. Fletcher R., Fletcher S., Vagner E. Klinicheskaya epidemiologiya. Osnovy dokazatel'noy meditsiny [Clinical epidemiology. Fundamentals of evidentiary medicine]. Moscow: Media Sfera, 1998. p. 352. (in Russian).

Клейн Светлана Владиславовна - кандидат медицинских наук, заведующий отделом системных методов санитарно-гигиенического анализа и мониторинга ФБУН «ФНЦ медико-профилактических технологий управления рисками здоровью населения», г. Пермь, тел. (342) 237-18-04; электронная почта: kleyn@fcrisk.ru, доцент кафедры экологии человека ФГБОУ ВПО «Пермский государственный национальный исследовательский университет».

Седусова Элла Викторовна - научный сотрудник ФБУН «ФНЦ медикопрофилактических технологий управления рисками здоровью населения», тел. (342) 237 18 04, электронная почта: makella@ fcrisk.ru.

Лебедева Татьяна Михайловна - доктор медицинских наук, профессор кафедры общественного здоровья и здравоохранения ГБОУ ВПО «Пермский государственный медицинский университет им. академика Е.А.Вагнера» Минздрава России, тел. (342) 233$25-31$. 
Новоселов Владимир Геннадьевич - доктор медицинских наук, профессор кафедры гигиены питания и гигиены детей и подростков ГБОУ ВПО «Пермский государственный медицинский университет им. академика Е.А.Вагнера» Минздрава России, тел.: (342) 2125-338, электронная почта: vnov2001@ mail.ru.

ФБУН «Федеральный научный центр медико-профилактических технологий управления рисками здоровью населения». Россия, 614045, г. Пермь, ул. Монастырская, 82

ФГБОУ ВПО «Пермский государственный национальный исследовательский университет», доцент кафедры экологии человека. Россия, 614990, г.Пермь, ул. Букирева, 15

ГБОУ ВПО «Пермский государственный медицинский университет им. академика Е.А.Вагнера» Минздрава России, Россия, 614990, г.Пермь, ул.Петропавловская, 26

Kleyn Svetlana Vladislavovna - Candidate of Medical Science, head of the department of sanitary and hygienic analysis and monitoring systemic methods, Federal Scientific Center for Medical and Preventive Population Health Risk Management Technologies, Perm, phone. (342)237-18-04; e-mail: kleyn@fcrisk.ru

Perm National Research Polytechnic University, Associate Professor, Department of Human Ecology.

Sedusova Ella Viktorovna - researcher, Federal Scientific Center for Medical and Preventive Population Health Risk Management Technologies, Perm, phone: (342) 237-18-04; e-mail: $\underline{\text { makella@fcrisk.ru }}$

Lebedeva Tatyana Mikhailovna - Doctor of Medical Science, professor of the department of public health and health care, Perm State Medical University named after E.A. Wagner, Perm, phone: (342) 233-25-31.

Novoselov Vladimir Gennadyevich - Doctor of Medical Science, professor, department of nutrition, children and teenagers` hygiene, Perm State Medical University named after E.A. Wagner, Perm, phone: (342) 21-25-338, e-mail: vnov2001@ mail.ru.

Federal Budgetary Scientific Institution "Federal Scientific Center for Medical and Preventive Population Health Risk Management Technologies”, 82, Monastyrskaya street, 614045, Perm, Russia.

Federal Budgetary Educational Institution of Higher Professional Training "Perm National Research University”, department of human ecology, 15, Bukirev street, 614990, Perm, Russia.

State Budgetary Educational Institution of Higher Professional Training "Perm State Medical University named after E.A. Wagner”, 26, Petropavlovskaya street, 614990, Perm, Russia. 